\title{
Changing Trends of Scientific Practices in India in the Twenty-first Century
}

\author{
Going Abroad for Acquiring Knowledge - How far is it true?
}

Most of the young scientists who go abroad say they are going for the sake of improving their knowledge. This statement does not seem to be wholly correct. The primary motivation invariably appears to be money, not directly perhaps, but in several other subtle ways. By securing a degree from a foreign university their monetary value increases and for a fellowship offered to an Indian student, the monetary value is substantial compared to the expenditure for higher education in India. When a student actually arrives in a foreign university, he is exposed to an intellectual atmosphere quite different from that prevailing in India and he has full freedom to select any course of his choice. The whole life of an Indian student in a foreign university is comparatively better in many respects as he puts longer hours in learning, takes new courses, spends much of time in libraries, and with such application, soon makes a mark. He may obtain a teaching assignment, with additional sources of income making him independent of remittances from home. By this time, he has adjusted to the new life, acquired a car and probably a flat, and his attachment to his mother country, always tenuous at best, gets easily snapped. Any amount of inducement from the parent country will not make him change his decision to remain abroad with the result that the benefits of 'higher education' are lost for his country. This is happening not only in the case of ordinary students but has happened in the case of S. Chandrasekhar, the noted Astrophysicist and a Nobel laureate who rejected the request of C.V. Raman to return to India and assume charge as Director of the Raman Research Institute and recently, in the case of Venky Ramakrishnan, the latest Noble laureate who has expressed no desire of returning to India. These are but two instances of exceptional talent denied to India and thus postponing the hopes of Indian science entering higher rank. The lure of money, freedom, comfort and a conducive atmosphere for carrying out high quality research further, new thoughts of effecting improvements by their own efforts bother them. They are eager to get back to their laboratories and to comfortable living conditions to which they are accustomed. The thought that advancement in science which they could provide and would improve the conditions of the poor and needy does not bother them. Wealth, fame and comfortable living are more important than rendering service.

\section{Scientific Societies}

The power of money is also subtly changing the complexion of working of our Science Societies. An example is the Geological Society of India, started more than fifty years ago, its aim was to bring together on a common platform for a free exchange of ideas, geologists working in Survey departments at Central and State levels, in the university geology departments and professional geologists engaged in consultancy service. A journal was started with the idea of publishing scientific work of significance in the best form possible and thus inform its members of advances in science in different parts of India and the world and to focus attention on the value of new findings and 
research in the fields of geology and mineral resources, with particular relevance to India. In the first twenty-five years, all work was honorary with the Editor typing his reports, packing them neatly and carrying them to the nearest post-office for registration. As Secretary, I attended to the miscellaneous jobs, kept in touch with the Press, packing and mailing of the journal to the members on the prescribed date, and such other miscellaneous duties. There was no laxity permitted and the journal was mailed on the due date without exception. After 25 years, the Society had the luxury of a clerk, a retired official with rich experience, on a nominal salary. As a matter of principle, we did not accept advertisements and the entire work of the Society was carried out on a frugal budget by persons who willingly lent their services without expectation of any reward except the satisfaction of a job well done.

\section{Advent of 'Online' Technology}

Meanwhile, conditions have changed. Commercial publishers have now entered the scene and new technologies have taken over the drudgery involved in printing and publishing. Men have become machines, doing a prescribed task in a prescribed time in a prescribed form and even the Editor of the Journal has become a part of the 'machine'. The time appears to have arrived when Journals in all likelihood disappear and all reading matter appearing 'online' with the click of a button. You can no longer sit relaxed in an easy-chair and peruse the pages of your favourite Journals and obtain a fair idea of what is happening in the rest of the world. New technology has made it possible to provide you with a facsimile of the paper in which you are interested by pressing a key. Online publication technology also provides the facility of reading sections of the paper you are interested in a laptop computer which you can carry wherever you go. The commercial publisher has developed various schemes to satisfy your needs. Libraries no longer stock copies of the earlier volumes. The pleasure of seeking information and, in the process coming to learn a great deal more of what is happening not only in your specialized field but science in general has all but stopped.

Whatever may be the advantages of this new technology, learned Societies and Academies should continue to bring out a hard copy of their Journals. They should give increasing importance to providing information to their members of all that is happening in India and other parts of the world in all branches of science. The 'Science' magazine of the American Association for the Advancement of Science and 'The Economist' of London are good models. The sole object of a Journal is to inform and educate and not just to make it a commercial venture. Societies do not seem to lay emphasis on the identification of young talent and providing them with ample scope for development.

\section{Paid Service of 'Event Managers'}

There is one other new development to which I must draw attention. An important activity of a learned Society is to organize symposia, periodically, on topics of special interest. The presentday tendency is to make the gatherings as large as possible and to include many delegates from abroad. Receiving the delegates, accommodating them in different hotels, guest houses and clubs, and bringing them to the meeting at the right time is a big responsibility involving the services of a large number of volunteers. Now, in the modern age of super-technology, all these headaches of an 
organization do not cause any worry. There is now a tribe of 'Event Managers' who, on payment of a substantial fee, take on their shoulders almost all aspects of the event organization. They fix the venue of the inaugural meeting and the order in which the chief guests are to be seated on the dais. One grand function will be arranged for the inauguration, followed by another for the release of the abstract volume and a keynote address is followed by lunch, the Event Manager giving his special attention to this part of the programme.

No one, however, really appears interested in the proceedings and most of the abstracts are taken as read. Since the Event Manager is in full charge there is no scope for individuals to meet together and have a discussion on their common research findings.

In the early days of a Society, the participating members were small in number and there was ample scope for meeting and exchanging of ideas. New contacts were established, new ideas exchanged and newer programmes chalked out. The volunteers, mostly junior members of the staff and research students, gained a great deal by their close association with the dignitaries whom they only knew by name.

This is another instance of service giving place to money power. The proceedings are now conducted with clock-like precision with delegates looked after well, their accommodation being made in star-hotels. Conducted tours are arranged for ladies accompanying the delegates and evening cultural programme arranged, followed by dinner. Everyone is properly taken care of and there is great satisfaction among the delegates and a greater relief on the part of organizers.

But what of the science part? Were new ideas projected? Were new procedures outlined? Were new advances made? The general readership of the Journal continues to remain ignorant. A short note on the event does appear in the Journal but is least informative, it being a larger version of the contents page, invitation, titles of the paper and the persons who spoke and a group photo showing the size of the gathering. The photograph of persons sitting on the dais at the inaugural function is a must and is prominently displayed.

The rights for publication of the papers contributed are also taken care of by a commercial publisher who fixes a price for the book which is almost always beyond the reach of most Fellows. 'Online' version of any paper is available on payment to the publisher. All efforts are reduced to a mechanical routine so that the opportunity of developing personal contacts and, in a few cases, building up an everlasting friendship is gradually being lost.

Closely associated with the subject of publications of scientific papers in the Journals is the question of getting a high rank in the Citation Index. No scientist seeking promotion to a higher post will ever think of publishing in a journal with a low citation index. A Journal is also judged by the number of highly cited papers it publishes. This is a new yardstick which has come to the aid of Scientific Committees constituted for selecting candidates for a senior post. It is argued that the person who has secured the maximum citation for his paper in Journals with a high citation index is a fitter person than the one without such a qualification. Ambitious scientists who aspire for the higher positions, look for ways and means to get their papers published in journals with a high citation index and large circulation. This is where the commercial publisher steps in with his rich experience in the art of marketing, he takes steps to suggest an attractive cover and a well-structured layout, improving the quality of paper and printing. Photos are printed on glossy paper and maps in attractive colours. Since modern technology has made it possible to place the entire journal 'online', 
the reader has the advantage of selecting only papers in which he is interested and can ask for any number of reprints (which the publisher is willing to supply at extra cost). Authors are then able to distribute copies to fellow scientists working on subjects of common interest and then gain the attention of all persons engaged in a particular line of research. Hopefully, if the recipient takes the trouble of reading the paper, the chances are that, in all likelihood, will cite your paper in his own. The object of making your paper cited by many is thus achieved.

\section{Discussion - Cornerstone of Scientific Argument and Debate, neglected}

While on the subject of citation, I should mention one serious shortcoming of our scientists their neglect either to comment or criticize or to point out mistakes in a published paper. In the case of a young scientist taking his first steps in research, a good word praising the novelty of his approach infuses tonnes of confidence in him. The whole complexion of his efforts gets a tremendous boost. Even a hardened writer like me, who has developed immunity to praise or condemnation, cannot suppress a sense of satisfaction when a worker wholly unknown to me says a few good words about my notes. J.B.S. Haldane, the noted geneticist, particularly emphasized this failure of Indian scientists. 'The reason why science in India was developing with disappointing slowness' he said 'was because of their reluctance to offer a critique of the work of others, especially those with an established reputation'. This comment of Haldane has not been taken seriously. Our scientists continue to remain mute neither commending authors for their good work or criticizing a work full of mistakes.

\section{Motivation for Study of Earth Sciences}

Science, especially Earth science, is no longer even a major career option. A filmmaker, football player, tennis star, or with a talent for sports is guaranteed a career. A cricketer who can pile up runs is in great demand, earning fabulous sums of money while information technology industry attracts young talent with attractive salaries from the very start. The medical profession is in great demand, requiring number of specialists to operate the various diagnostic equipments and offering unlimited amounts of money. Televised sport has become a powerful money-making machine. Governments in Delhi and the States are indifferent to mining and mineral development. Full development of a mature nation requires effective utilization of all resources, not just those which are readily accessible without much effort, such as coal, iron and manganese ore and bauxite. What motivation is there now for the youth to take up a career in geology or mineral development? Those who control geology in India today should seriously consider these aspects and take appropriate action to restore the science of the Earth to a position of importance.

I have taken the liberty of pointing out a few instances where Science Societies and Academies seem to be deviating from the path of rendering service to fellow scientists by not bringing to their notice the significant advances made in different branches of science and also by not outlining developments in other parts of the world but instead are transferring their responsibilities to commercial organizations on promise of increased circulation and revenue. The subject is of great importance and should be discussed freely. 